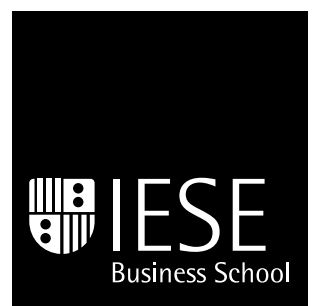

University of Navarra

\title{
ENTREPRENEURIAL BEHAVIOUR \\ IN A LARGE TRADITIONAL FIRM: EXPLORING KEY DRIVERS
}

\author{
Johanna Mair*
}

RESEARCH PAPER No 466

June, 2002

* Professor of General Management, IESE

\section{Research Division}

IESE

University of Navarra

Av. Pearson, 21

08034 Barcelona - Spain 


\title{
ENTREPRENEURIAL BEHAVIOUR IN A LARGE TRADITIONAL FIRM: EXPLORING KEY DRIVERS
}

\begin{abstract}
Innovative use of resources to pursue opportunities has become vital for all organizations. Even large traditional firms operating in stable and mature markets increasingly stress entrepreneurial initiative as a key element in their strategic long-term orientation.

While traditional management literature has identified contextual features that foster entrepreneurial activity, little research has looked at why -in the same objective organizational context- some managers act entrepreneurially and others do not. I recognize the importance of context in shaping managerial behaviour. However, while differences in the behavioural context might explain variance in entrepreneurial behaviour between companies, they fail to explain variance within the same company.

Drawing on literature in entrepreneurship, strategic management, organizational behaviour and social cognitive theory, I present a model on the micro-foundations of entrepreneurial behaviour in large traditional organizations. I propose that entrepreneurial behaviour is largely affected by managers' subjective interpretations of their supportive context and their set of cognitive and emotional characteristics. Furthermore -acknowledging a proactive role of individuals in controlling their own behaviour and cognition- I introduce entrepreneurial self-efficacy beliefs -defined as managers' perceived capability to perform entrepreneurial tasks- as a critical influencer of actual entrepreneurial behaviour.
\end{abstract}

I empirically test this model and use structural equation modeling (SEM) to analyze data from 150 middle managers of a large European financial service company striving to become "entrepreneurial". Preliminary findings reveal that managers' subjective interpretations of their sociopolitical support and access to resources significantly stimulate entrepreneurial behaviour. Contrary to the predictions of the literature, individual cognitive and emotional characteristics do not affect entrepreneurial behaviour directly, but are critical in shaping managers' perceptions of their "playground for action". Furthermore, findings suggest that managers' entrepreneurial self-efficacy beliefs are a powerful predictor of entrepreneurial behaviour. They are critical to translate perceptions of context and individual characteristics into behaviour, and represent an important cognitive and motivational device to steer and regulate entrepreneurial behaviour.

Based on an explorative yet rigorous research design, this study broadens our understanding of the main determinants of entrepreneurial behaviour within established organizations and consolidates various streams of literature. Last but not least, it offers valuable insights for managerial practice on how to encourage entrepreneurial behaviour across multiple levels of the organization.

Keywords: entrepreneurship, intrapreneurship, emotional intelligence, self-efficacy. 


\section{ENTREPRENEURIAL BEHAVIOUR IN A LARGE TRADITIONAL FIRM: EXPLORING KEY DRIVERS}

\section{Introduction}

Entrepreneurial behaviour -innovative use of resources to pursue opportunities- is widely seen as vital for "virtually all" sizes and types of organization (Dess et al., 1999). While prior studies have to a large extent focused on contextual features to explain entrepreneurial behaviour, little research has looked at the puzzling phenomenon of why some managers act entrepreneurially and others, being exposed to the same organizational context, do not. In this paper I advance and empirically test the idea that managers' subjective interpretation of context and their ability to regulate feelings, thoughts, and actions account for variance in entrepreneurial behaviour within the same objective organizational context.

Traditional definitions of entrepreneurial behaviour within existing firms are typically restricted to discrete entrepreneurial events such as new venture creation or new product development. While important, narrowly defined notions of grand entrepreneurship remain inapplicable to various entrepreneurial phenomena occurring in large established firms. In this study I adopt a less heroic view and emphasize day-to-day entrepreneurship aiming at "getting things done in an entrepreneurial -innovative and unusual- way". Building on a behavioural research tradition (Stevenson et al., 1990), I define entrepreneurial behaviour within existing organizations as a set of activities and practices by which individuals at multiple levels autonomously generate and use innovative resource combinations to identify and pursue opportunities.

While innovation, autonomy and opportunities are defining elements of entrepreneurship in general (Stevenson et al., 1990), entrepreneurial behaviour within large traditional organizations is distinct. It includes a spectrum of activities ranging from independent/autonomous to integrative/cooperative behaviour (Ghoshal et al., 1994). Within large traditional organizations "entrepreneurial managers" need to build on the uniqueness of their units and at the same time profit from similarities with other units. They continuously need to balance "exploration" of new resource combinations with "exploitation" of existing organizational capabilities. Opportunities to act entrepreneurially arise within and outside the organization. As such managers can become entrepreneurial, first, in they way they lead and guide their subordinates, second, in the way they build and organize their unit, and last but not least, in the way they meet challenges from customers and markets (Mair, 2001). It is the set of these activities -constituting entrepreneurial behaviour- that is at the center of this study. 


\section{Theoretical framework and hypotheses}

Identifying the origins of entrepreneurial initiative has attracted the attention of scholars in various fields of research. Two perspectives in particular have contributed to our current understanding of what induces entrepreneurial behaviour in traditional organizations. One stream of research, labeled here as the macro view, focuses on the firm as the primary level of analysis and contests that "context triggers entrepreneurial behaviour". The second stream of research, labeled as the micro view, centers on the individual and asserts, "personal characteristics determine entrepreneurial behaviour". This study aims at reconciling and expanding both views. In the following sections I introduce and empirically test a framework that emphasizes managers' individual perceptions of supportive context and their ability to monitor action, cognition, and emotions as important influencers of entrepreneurial behaviour.

\section{Direct Effects}

\section{The Macro View}

Research on the role of context in promoting entrepreneurial initiative within firms became increasingly popular in the 1980s and early 1990s. The message conveyed by almost all studies is unequivocal: support is critical to induce entrepreneurial behaviour in large traditional organizations (Ghoshal et al., 1994; Kuratko et al., 1990). Supportive context is typically viewed as a multidimensional construct composed of four sub-dimensions: freedom to act (Lumpkin et al., 1996), access to resources (Kanter, 1985), access to information (Churchill et al., 1994), and socio-political support (Kuratko et al., 1990). However, while the "ideal" contextual features identified by this stream of research might explain variance in entrepreneurial behaviour between firms, they do not elucidate why, within the same organizational context, some manager act entrepreneurially and others do not. In other words, the fact that different managers might perceive the same objective supportive context very differently is barely considered. Empirical and theoretical findings, however, reveal that the way individuals interpret and perceive their "playground" for action guides their (entrepreneurial) behaviour and influences performance (Brazeal, 1993). I explicitly consider the importance of managers' perceptions of their supportive context in stimulating entrepreneurial behaviour and propose:

Hypothesis 1: Managers' perceptions of their supportive context have a direct, positive effect on entrepreneurial behaviour.

In particular, I propose a positive effect of managers' perceived freedom to act, their perceived socio-political support, and their perceived access to information and resources on entrepreneurial behaviour.

\section{The Micro View}

While it is widely accepted that individual characteristics matter (Stevenson et al., 1990), prior research has predominately focused on innate personality traits -locus of control, need for achievement or risk-taking- to explain entrepreneurship. Recent studies in organizational behaviour, however, emphasize malleable individual variables -dynamic in space and time- as key influencers of managers' behaviour. In particular, cognitive and emotional variables to do with recognition, regulation and expression of thoughts and 
feelings are seen as vital to understand the increasingly complex behaviour in today's business organizations (Fox et al., 2000). Given the complex nature of entrepreneurial behaviour, I confine my analysis to a set of individual variables, often referred to as "emotional intelligence", i.e., the ability to monitor one's own and others' feelings and emotions, to discriminate among them, and to use one's information to guide one's thinking and actions (Salovey et al., 1990). Although systematic empirical research on emotional intelligence is still rare, four well-studied variables have been frequently associated with the ability to regulate thoughts and feelings: self-monitoring and perspective taking, both referring to cognitive aspects; and emotional self-awareness and positive emotions at work, two variables capturing emotional aspects.

Self-monitoring refers to the tendency to observe and control one's expressive behaviour, self-presentation and non-verbal displays of emotion and affect (Snyder, 1979). High self-monitors adapt better to changing situations and therefore may also do better in switching between different tasks, constituting entrepreneurial behaviour. Perspective taking -the cognitive dimension of empathy- reflects the ability to adopt the perspective, or point of view, of other people (Davis, 1980). "Perspective takers" are more likely to cooperate, an important component of entrepreneurial behaviour within large organizations. Isen et al. (1991) point to robust empirical evidence on the effect of positive emotions on creativity and divergent thinking on the one hand, and on cooperative and helping behaviour on the other -both major building blocks of entrepreneurial behaviour within traditional organizations. Last but not least, emotional self-awareness -individuals' ability to recognize their own emotions and their effects (Goleman, 1998)- has been positively linked with entrepreneurship (Baron, 1998). Based on these theoretical arguments and empirical findings, I propose:

Hypothesis 2: Managers' ability to monitor their own feelings and thoughts has a direct, positive effect on entrepreneurial behaviour.

\section{Indirect Effects}

The basic claim of this paper is that both perceptions of supportive context and individual cognitive and emotional characteristics matter. However, their effect on entrepreneurial behaviour might not merely be as straightforward or direct as suggested by previous literature. Previous research has suggested that personality characteristics don't exert an isolated effect but work in conjunction with others (Naffziger, 1995). Building on this I consider two indirect effects. First, I speculate that managers' set of cognitive and emotional variables significantly shapes their perceptions of supportive context, which in turn affect entrepreneurial behaviour:

Hypothesis 3: Managers' set of individual variables to monitor feelings and thoughts significantly shapes their perceptions of supportive context.

In more detail: I propose that high levels of self-monitoring, perspective taking, positive emotions at work, and emotional self-awareness positively affect managers' perceptions of their supportive context (see Figure 1 for the complete set of hypotheses). 
Figure 1. Model for Empirical Testing

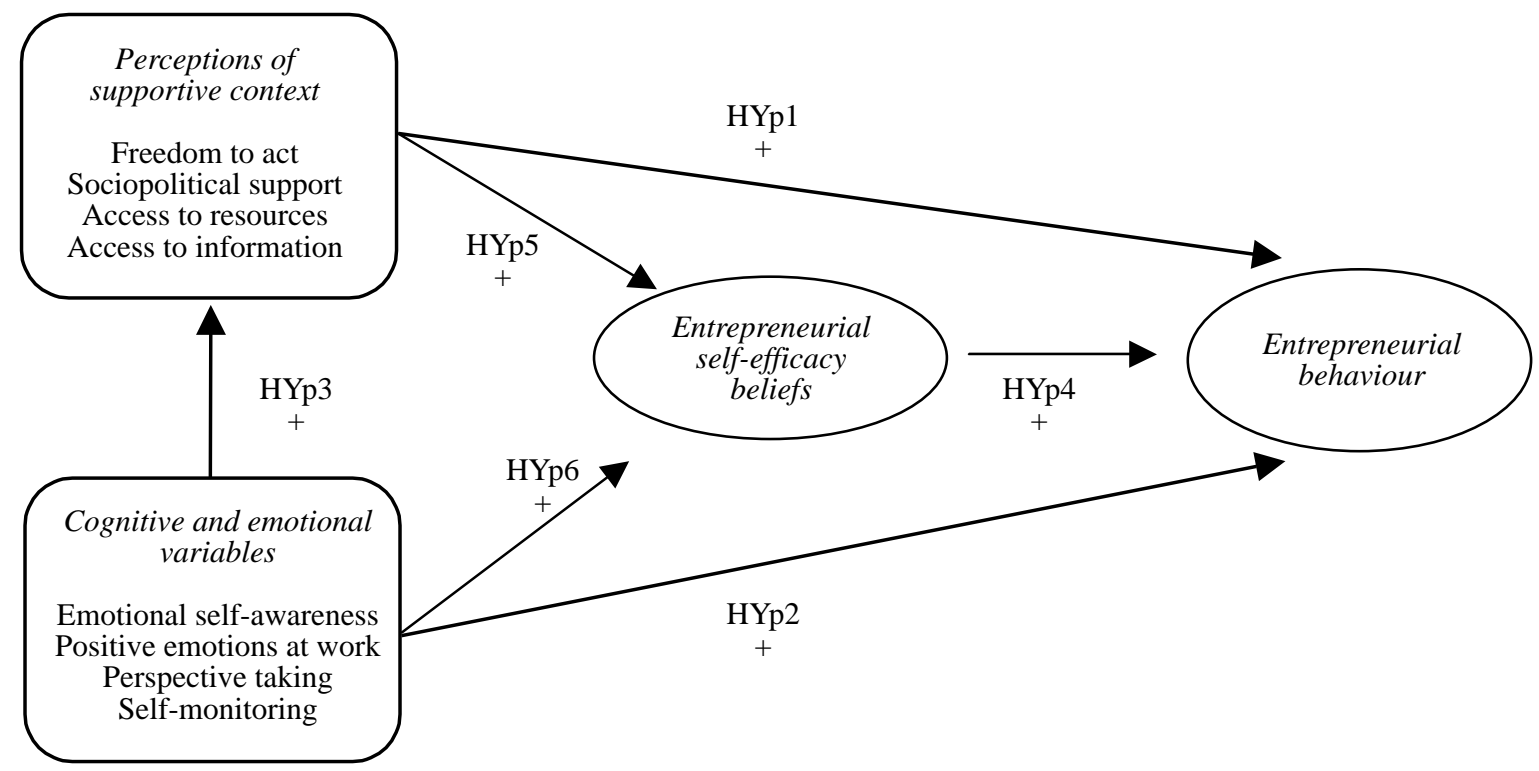

Second, I introduce entrepreneurial self-efficacy beliefs -managers' perceived ability to perform entrepreneurial tasks- as a mediating variable to translate individual characteristics and perceptions of supportive context into actual behaviour. Self-efficacy beliefs are conceived as a central construct in examining behavioural self-regulation, i.e., the cognitive, individual determination of behaviour (Wood et al., 1989). They have been considered as highly relevant to the study of entrepreneurial phenomena (Stevenson et al., 1990). Based on a number of empirical studies suggesting a positive relationship between entrepreneurial self-efficacy beliefs and entrepreneurial activities (Baum, 1994; Chen et al., 1998), I propose:

Hypothesis 4: Entrepreneurial self-efficacy beliefs have a direct, positive effect on entrepreneurial behaviour.

To successfully assess self-efficacy beliefs and their impact on behaviour, personal and contextual factors must be considered (Gist et al., 1992). Accordingly, I suggest that entrepreneurial self-efficacy beliefs assume a mediating role in translating perceptions of support and emotional and cognitive variables into entrepreneurial behaviour.

Theoretical support for linking perceptions of supportive context and cognitive and emotional variables on the one hand, and entrepreneurial self-efficacy beliefs on the other, goes back to the main sources of self-efficacy as identified by the literature. Traditional literature on self-efficacy has identified four primary information cues that foster selfefficacy beliefs, namely, enactive mastery (repeated performance accomplishment), vicarious experience (modeling), verbal persuasion (convincing), and psychological state (physiological and emotional arousal) (Wood et al., 1989). 
Perceived freedom to act strengthens efficacy beliefs as it facilitates internalization of behavioural goals through enactive mastery of entrepreneurial tasks. Perceived sociopolitical support positively affects self-efficacy beliefs via two important information cues, namely, verbal persuasion and vicarious experience. Managers who perceive their formal and informal network as supportive are, first, more easily convinced and open to verbal persuasion, and second, more inclined to adopt new behavioural patterns through vicarious experience, i.e., to learn from other members in the network. Positive perceptions of access to information enhance managers' judgment of their entrepreneurial capabilities by providing a more accurate understanding of task attributes, complexity and environment (Gist et al., 1992). Last but not least, managers' perceptions of access to resources create a sense of control over environmental contingencies and therefore enhance perceived self-efficacy (Gist et al., 1992). Integrating these insights with the previous theoretical arguments, I propose:

Hypothesis 5: Managers' perceptions of supportive context exert a positive effect on entrepreneurial self-efficacy beliefs and therefore indirectly influence entrepreneurial behaviour.

Self-monitoring influences self-efficacy beliefs through its impact on two information cues: high self-monitors are sensitive to outcomes of their own behaviour (enactive mastery) and the behaviour of others (vicarious learning). Perspective taking encourages individual control over the course of action, as it facilitates vicarious experience and verbal persuasion -two major information cues informing perceived self-efficacy. Positive emotions enhance persistence and cognitive functioning, which in turn increase the level of perceived self-efficacy and positively affect task activity (Staw et al. 1994). Knowing and recognizing their feelings, emotionally self-aware managers are better able to control their emotions, their cognition, and, last but not least, their actions. Being sensitive to their inner workings, managers are particularly concerned about their ability to effectively perform specific tasks. Accordingly, I propose:

Hypothesis 6: Managers' ability to monitor their own feelings and thoughts has a positive effect on entrepreneurial self-efficacy beliefs and therefore indirectly influences entrepreneurial behaviour.

In sum, to provide a comprehensive model for investigation, I consider direct effects -as suggested by the traditional literature- as well as indirect effects. Figure 1 summarizes the refined model for empirical investigation and illustrates the complete set of hypotheses.

\section{Methods}

I chose a one-company research design to attentively capture the phenomenon, and to develop context-specific measurement instruments. It also allowed me to reduce "noise" by holding constant several important determinants of entrepreneurial behaviour at the firm level, such as incentives systems, corporate culture, official information flows.

\section{Setting \& Sample}

In 1997, ABN Amro -a large Dutch financial service company- launched a project to promote entrepreneurial behaviour, and accordingly reshuffled its operations in the Netherlands. It split the domestic market into approximately 200 micro markets 
and appointed an area manager for each of these newly created independent units. These 200 managers, who were expected to act entrepreneurially -to explore and exploit opportunities by innovative use of resources- are at the center of this study.

I conducted a survey to assess their entrepreneurial behaviour, their entrepreneurial self-efficacy beliefs, and their ability to control thoughts and feelings, as well as their individual perceptions of supportive context. Hundred-and-fifty managers answered the questionnaire (response rate of $72 \%$ ). I evaluated non-response biases by comparing regional distribution, size, and performance of the units in the "returned" sample with the ones in the "not-returned" sample. No significant differences were found. As suggested by the relevant literature, I eliminated social desirability effects as much as possible by clarifying introductions and accurate phrasing of questions (Rossi et al., 1983).

\section{Measures}

Drawing on interviews with area managers, subordinates, bosses and internal/external experts, I built context-specific[M1] indicators to establish scales for entrepreneurial behaviour and entrepreneurial self-efficacy (see Mair (2001) for details on the methodology and the complete set of measurement instruments). The final scale for entrepreneurial behaviour included questions about the extent to which managers engaged in particular entrepreneurial activities targeted at renewing processes and design, guiding employees, and doing business and building a face in the market. I assessed entrepreneurial self-efficacy beliefs by asking respondents to indicate their level of confidence in their ability to perform specified entrepreneurial tasks. To capture and measure the various dimensions of perceived supportive context, I developed specific indicators for perceived freedom to act, and perceived access to information and resources, and adapted an existing scale of perceived socio-political support (Spreitzer, 1992). To assess cognitive and emotional characteristics I adapted existing scales for self-monitoring (Lennox et al., 1984), perspective taking (Davis, 1980), positive emotions at work (Staw et al., 1994), and emotional self-awareness ("BarOn Emotional Quotient Inventory"). All measures are based on seven-point Likert-type scales, with the exception of entrepreneurial self-efficacy beliefs, which, following the suggestion of the literature, is based on a ten-point scale (Lee et al., 1994).

\section{Results}

Descriptive statistics and correlations are shown in Table 1. Internal consistency, average variance extracted (convergent validity), and discriminant validity are reported in Table 2. According to the guidelines established by (Fornell et al., 1981) all scales demonstrate adequate levels. Factor analysis revealed one common factor for each construct with items adequately correlated. Squared multiple correlations (SMC's) for entrepreneurial behaviour and entrepreneurial self-efficacy beliefs exhibit a highly satisfactory fit. The proposed model explains $43 \%$ of the variance in entrepreneurial behaviour of area managers, which is particularly satisfactory given the complexity of managerial behaviour. In addition, almost half of the variance in entrepreneurial self-efficacy beliefs (45\%) was captured by the proposed model (see Figure 2). 
Figure 2. Results for Empirical Testing

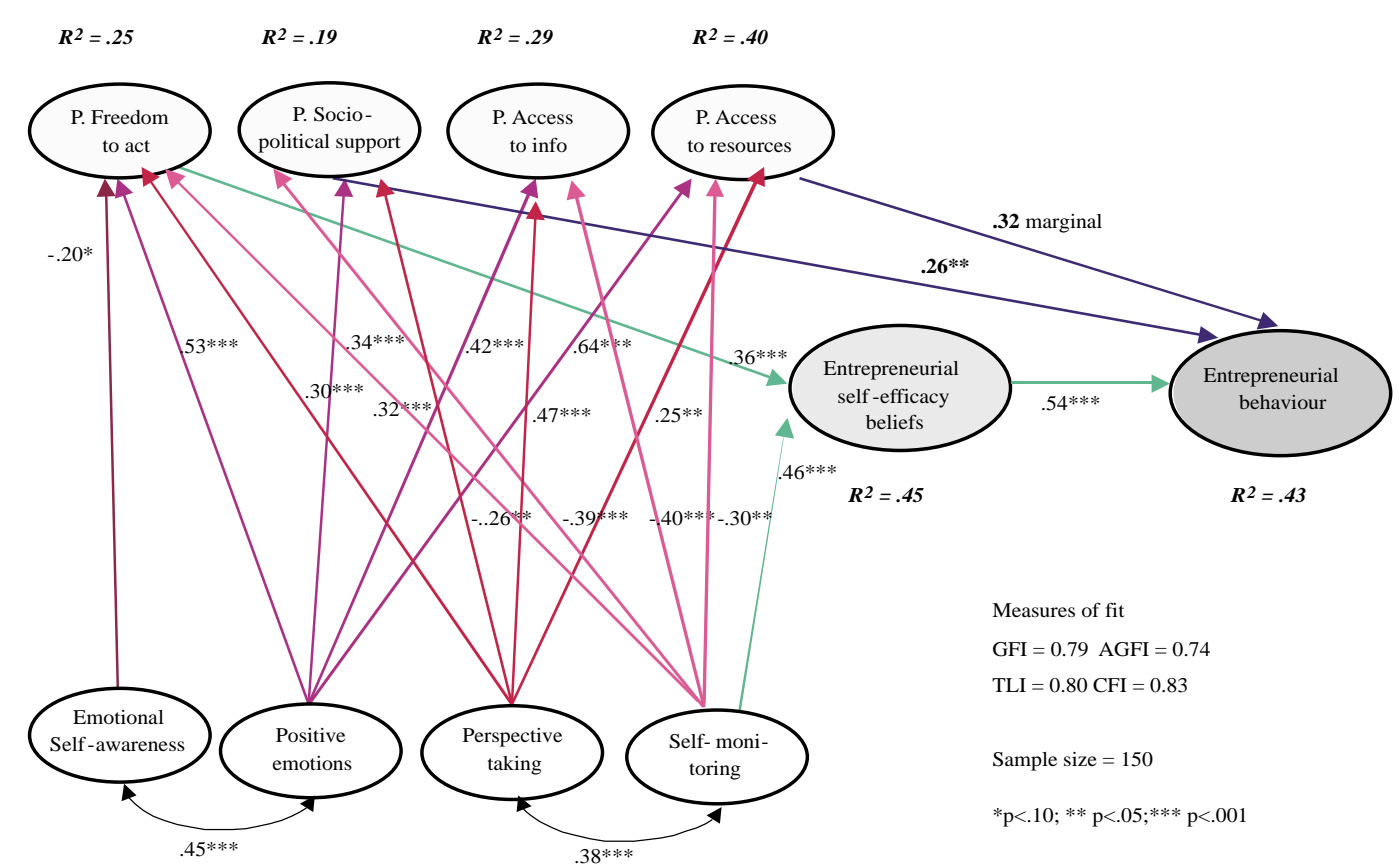

\section{Direct effects}

Perceived socio-political support exerted a positive and significant influence, and perceived access to resources had a positive and marginally significant influence on entrepreneurial behaviour. Contrary to previous studies in entrepreneurship and social psychology that portray entrepreneurial behaviour as determined primarily by individual characteristics, data analysis revealed no significant direct effect of cognitive and emotional variables on entrepreneurial behaviour.

\section{Indirect effects}

As predicted, the results revealed significant indirect effects. First, managers' cognitive and emotional variables significantly influenced the way they perceived their supportive context. Perspective taking and positive emotions influenced perceptions of supportive context in the expected positive manner. Self-monitoring instead exerted a significant negative influence on the different sub-dimensions of perceived supportive context, suggesting that managers with an enhanced ability to control their self-presentation are more likely to attribute their actions to themselves than to their environment and therefore tend to perceive their context as less supportive. Emotional self-awareness had a significant negative effect on only one subdimension, namely, perceived freedom to act. As no validated measure was available on this construct, the mixed results can be partly attributed to measurement error. The significant negative effect on freedom to act suggests that the higher managers score in emotional selfawareness, the more they feel determined by their emotions and the more negatively they perceive their freedom to act. 
Second, as hypothesized, entrepreneurial self-efficacy beliefs had a strong positive and highly significant impact on entrepreneurial behaviour, suggesting that entrepreneurial selfefficacy beliefs are a powerful predictor of entrepreneurial behaviour. Furthermore, the data partly supported the mediating role of self-efficacy in translating perceptions of supportive context and the ability to control thoughts and feeling into entrepreneurial behaviour. Two variables exhibited an indirect strong and highly significant influence on entrepreneurial behaviour: managers' ability to self-monitor own behaviour, and perceived freedom to act. Perceived access to resources had a positive and marginally significant influence.

I controlled for potential sources of heterogeneity: tenure as area managers, number of years within ABN Amro, age, gender, salary, size and geographical location of the area. A number of control variables had a significant direct and negative effect on perceived supportive behavioural context. One (age) had a significant and negative effect on perceived self-efficacy, but none of the control variables had a significant impact on entrepreneurial behaviour. Overall, the stability and robustness of previous results remained largely unaffected.

\section{Discussion and limitations}

Drawing on interdisciplinary literature, I developed and empirically tested a model of the micro-foundations of entrepreneurial behaviour within large traditional organizations. Data on 150 managers striving to become more "entrepreneurial" revealed that the way managers perceive their supportive organizational context -notably their perceptions of support from colleagues, peers and bosses, as well as access to resources- significantly influences entrepreneurial behaviour. Perceptions of supportive context, in turn, are shaped by managers' ability to monitor their own feelings and thoughts. This suggests, first, that managers create their "playground for action" in their own minds, and second, that it is these subjective interpretations of supportive context that determine entrepreneurial behaviour.

Findings also accentuate the importance of entrepreneurial self-efficacy beliefs -defined as perceived capability to successfully perform entrepreneurial tasks- as a powerful predictor of entrepreneurial behaviour. They assume an important mediating role in translating managers' ability to self-monitor and their perceptions of freedom to act into entrepreneurial behaviour. My findings furthermore suggest that entrepreneurial self-efficacy beliefs are a powerful predictor of actual entrepreneurial behaviour and represent an "inner compass" -an important cognitive and motivational device - to steer and regulate entrepreneurial behaviour.

\section{Limitations}

This paper advances existing research on entrepreneurial behaviour in established firms by focusing on "day-to-day entrepreneurship" at the sub-unit level. It reconciles traditional "micro" and "macro perspectives" and sets the stage for future multilevel research on this phenomenon. However, a few limitations should be pointed out. First, as the study and some of the measures are based on a one-company study, it is difficult to account for external validity and to derive generalizations on entrepreneurial behaviour in traditional organizations. Second, to examine the micro-foundations of entrepreneurial initiative, I concentrated on perceptual data. Several problems of self-reported data, such as common method bias, consistency motif and social desirability, have been repeatedly pointed out. Following relevant literature, I reduced such biases through careful design of questionnaire items, "scale 
reordering" (measuring dependent variables first), "scale trimming" (eliminating items that overlap with other measures), and use of different scale formats. In the context of self-reported data, difficulties in measurement arise especially for variables concerning individual dispositions (Podsakoff et al., 1986). For instance, it is questionable whether respondents are able to express feelings as ratings on a scale (Isen et al., 1991). A third limitation of this study consists in the reciprocal nature of the relationships between constructs. Entrepreneurial selfefficacy beliefs, for example, can be perceived as both an antecedent and a consequence of entrepreneurial behaviour (Wood et al., 1989). Finally, the cross-sectional nature of the survey data impedes insights on time-related issues, and causal effects cannot be assessed.

\section{Managerial Implications}

Meaningful implications for managerial practice can be derived. My study corroborates earlier findings suggesting that managers interpret, and give subjective meaning to, objective organizational context and therefore "construct" their own behavioural context (Weick, 1979). Perceptions, however, are learned and learnable (Krueger et al., 1994), and top management can facilitate change towards entrepreneurial behaviour by influencing this "sense-making" process. Findings also reveal that entrepreneurial self-efficacy beliefs provide an explanation for why some managers act entrepreneurially while others, in the same objective organizational context, do not: it is not because these mangers lack necessary skills but because they do not believe in their capabilities to perform entrepreneurial tasks. Thus, identifying and removing such "self-doubts" is critical to enact entrepreneurial behaviour (Chen et al., 1998). Previous research has shown that favorable self-efficacy beliefs are readily teachable and that these amplified perceptions of self-efficacy persist over time (Gist, 1987). Top management can deliberately influence the primary sources of entrepreneurial self-efficacy beliefs by, for example, structuring behavioural change programs in such a way that initial objectives are easily attainable and can be executed successfully. This allows managers more easily to accomplish behavioural goals, which in turn reinforces self-efficacy beliefs (Beer, 1980).

\section{References}

Baron RA. 1998. Cognitive mechanisms in entrepreneurship: Why and when entrepreneurs think differently than other people. Journal of Business Venturing 13(4): 275-294.

Baum JR. 1994. The relation of traits, competencies, vision, motivation, and strategy to venture growth. University of Maryland.

Beer M. 1980. Organizational change and development. Goodyear: Santa Monica, CA.

Brazeal DV. 1993. Organizing for internally developed corporate ventures. Journal of Business Venturing 8(1): 75-90.

Chen CC, Greene PG, Crick A. 1998. Does entrepreneurial self-efficacy distinguish entrepreneurs from managers? Journal of Business Venturing 13(4): 295-316.

Churchill NC, Muzyka DF. 1994. Entrepreneurial Management: A Converging Theory For Large And Small Enterprises, Frontiers of Entrepreneurship Research. Center for Entrepreneurial Studies Babson College. 
Davis MA. 1980. A multidimensional approach to individual differences in empathy. JSAS Catalog of Selected Documents in Psychology 10(85).

Dess GG, Lumpkin GT, McGee JE. 1999. Linking corporate entrepreneurship to strategy, structure, and process: Suggested research directions. Entrepreneurship Theory and Practice 23(3): 85-102.

Fornell C, Larcker DF. 1981. Evaluating Structural Equation Models with Unobservable Variables and Measurement Error. Journal of Marketing Research XVIII: 39-50.

Fox S, Spector PE. 2000. Relations of emotional intelligence, practical intelligence, general intelligence, and trait affectivity with interview outcomes: It's not all just ' $G$ '. Journal of Organizational Behaviour 21(Special Issue): 203-220.

Ghoshal S, Bartlett C. 1994. Linking Organizational Context and Managerial Action: The Dimensions of Quality of Management. Strategic Management Journal 15: 91-112.

Gist ME. 1987. Self-Efficacy: Implications for Organizational Behaviour and Human Resource Management. Academy of Management Review 12(3): 472-485.

Gist ME, Mitchell TR. 1992. Self-Efficacy: A Theoretical Analysis of its Determinants and Malleability. Academy of Management Review 17: 183-211.

Goleman D. 1998. Working with Emotional intelligence. Bloomsbury: London.

Isen AM, Baron RA. 1991. Positive Affect as a factor in Organizational Behaviour. Research in Organizational Behaviour 13: 1-53.

Kanter RM. 1985. Supporting innovation and venture development in established companies. Journal of Business Venturing 1: 47-60.

Krueger NFJ, Brazeal DV. 1994. Entrepreneurial potential and potential entrepreneurs. Entrepreneurship Theory and Practice (Spring): 91-104.

Kuratko DF, Montagno RV, Hornsby JS. 1990. Developing an intrapreneurial assessment instrument for an effective corporate entrepreneurial environment. Strategic Management Journal 11: 49-58.

Lee C, Bobko P. 1994. Self-Efficacy Beliefs: Comparison of Five Measures. Journal of Applied Psychology 79(3): 364-369.

Lennox RD, Wolfe RN. 1984. Revision of the Self-Monitoring Scale. Journal of Personality and Social Psychology 46: 1.349-1.364.

Lumpkin GT, Dess GG. 1996. Clarifying the entrepreneurial orientation construct and linking it to performance. Academy of Management Review 21(1): 135-172.

Mair J. 2001. Entrepreneurial Behaviour in A Large Traditional Organization: Exploring Nature, Key Drivers and Performance Implications, Department of Strategy. INSEAD: Fontainebleau. 
Naffziger DW. 1995. Entrepreneurship: A person based theory approach. In Katz \& Brockhaus (Ed.), Advances in entrepreneruship, firm emergence, and growth, Vol. 2: 21-50. JAI Press: Greenwich, CT.

Podsakoff PM, Organ DW. 1986. Self-Reports in Organizational Research: Problems and Prospects. Journal of Management 12(4): 531-544.

Rossi PH, Wright JD, Anderson AB (Eds.). 1983. Handbook of Survey Research. Academic Press Inc: San Diego.

Salovey P, Mayer JD. 1990. Emotional Intelligence. Imagination, Cognition and Personality 9(3): 185-211.

Snyder M (Ed.). 1979. Self-Monitoring Processes. (Vol. 12). Academic Press: New York.

Spreitzer G. 1992. When Organizations Dare: The Dynamics of Individual Empowerment in the Workplace, Organizational Behaviour. University of Michigan: Ann Arbor.

Staw BM, Sutton RI, Pelled LH. 1994. Employee positive emotion and favorable outcomes at the workplace. Organization Science 5: 51-71.

Stevenson HH, Jarillo JC. 1990. A paradigm of entrepreneurship: entrepreneurial management. Strategic Management Journal 11: 17-27.

Weick K. 1979. The Social Psychology of Organizing. Random House: New York.

Wood R, Bandura A. 1989. Social Cognitive Theory of Organizational Management. Academy of Management Review 14(3): 361-384. 


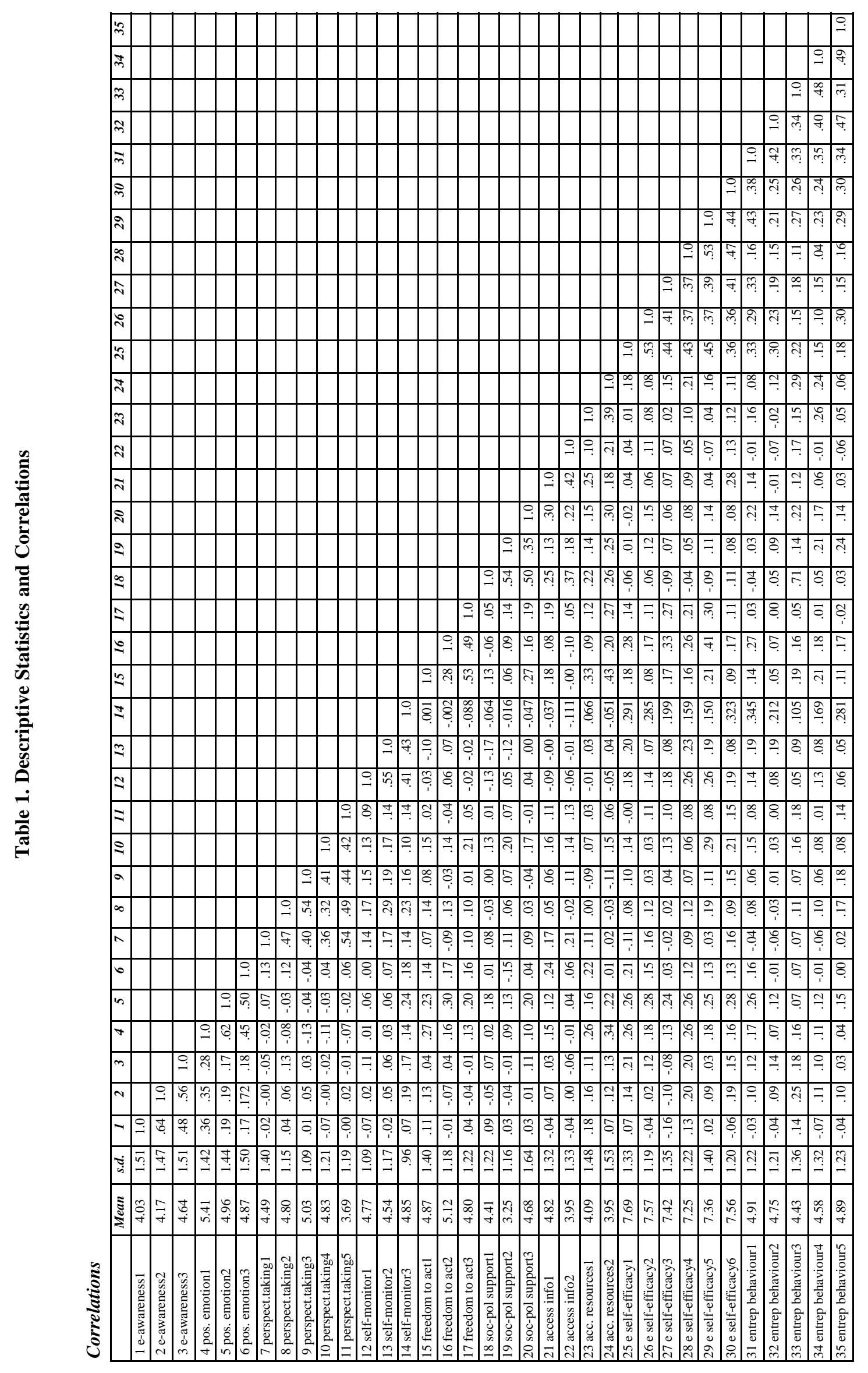




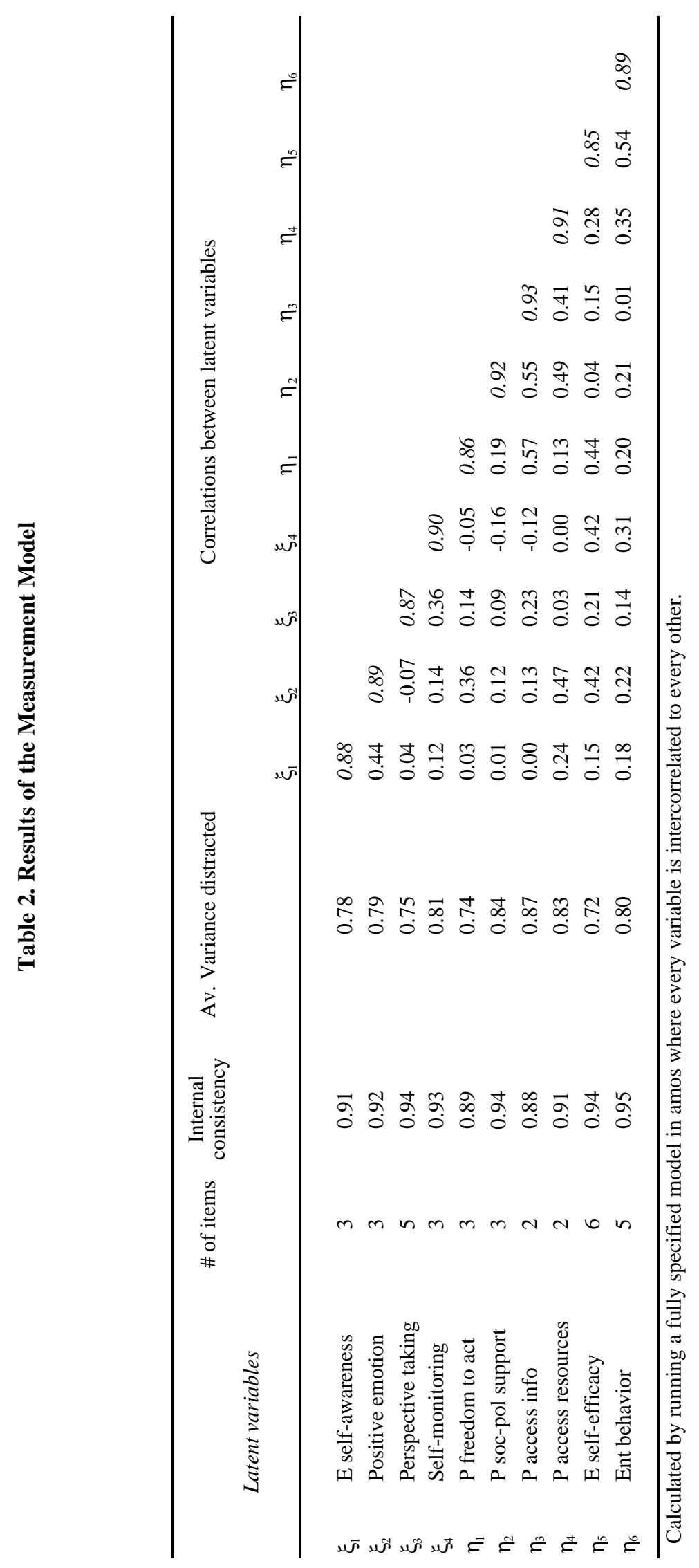

